\title{
Design and Development of Energy Efficient Re-roofing Solutions
}

\author{
Shahryar Habibi ${ }^{\text {a }}$, Esther Obonyo ${ }^{\mathrm{b}}$, Ali M. Memari ${ }^{\mathrm{c}}$ \\ ${ }^{\text {a }}$ University of Ferrara, Italy \& The Pennsylvania State University, USA \\ b, c The Pennsylvania State University, USA \\ a hbbshr@unife.it, ${ }^{\mathrm{a}}$ sxh707@psu.edu, ${ }^{\mathrm{b}}$ eao4@psu.edu, \\ camm7@psu.edu
}

\begin{abstract}
In the past decade, there has been considerable growth in the retrofit of existing roofs for energy and sustainability improvements. Although the study of roof systems (from coverings to structure) is of great significance to energy efficiency and sustainable development, design and construction of new roofs on top of existing roofs in buildings has not received sufficient attention. This work attempts to present a case study of an innovative and energy efficient design for dealing with challenges of integrating the new components with the existing deteriorated roof of a building in New Kensington, PA to prevent water leakage and harvest solar energy. The study uses green retrofit and sustainability-inspired initiatives such as designing and testing a conceptual model for a new roofing composite that will sit on top of the existing roof not only to improve the aesthetic qualities and thermal insulation but also to add renewable energy production capability. There is considerable potential to improve energy efficiency of existing buildings by replacing or retrofitting an existing roof. For example, a roof energy audit can provide an effective contribution to building energy efficiency retrofits. In this work, an energy assessment of the proposed prototype is used to assess the extent to which thermal insulation materials can contribute to sustainable energy retrofitting strategies for the existing roofs.
\end{abstract}

\section{Introduction}

In order to develop a more holistic method for energy efficient refurbishment of buildings, it is necessary to focus on decision-making processes particularly with regard to building envelope elements such as walls, roofs, foundations, windows, doors, and chimneys. A study by Roberts et al. (2015) highlighted how the envelope quality is a crucial point in all refurbishment actions.

Retrofit and refurbishment strategies are necessary to make energy efficiency improvements and cost reduction initiatives for buildings. Regarding materials and waste, studies show that the environmental impact of life cycle extension of a building is less than demolition and new construction (Thomsen and van der Flier, 2008). In other words, it is important to target the existing buildings for energy efficiency retrofits as a cost-effective approach to reduce the building sector's environmental impact and greenhouse gas emission.
A study by Cascone et al. (2018) highlighted the current structural limits for retrofitting of existing buildings and the adequacy of materials used. The study by Fan and Xia (2015) focused on designing a multi-objective optimization model for a building envelope-retrofitting plan. Zhou et al. (2016) sought effective ways of building energy efficient retrofitting based on one year of monitoring. Chen et al. (2019) reported that retrofitting roof systems may lead to better building performance overall, compared to retrofitting other elements of the building envelope. Moreover, the study indicated that selection of an appropriate insulation level is very important in order to achieve the optimal performance in the building retrofit.

Pisello et al. (2015) developed a cool-green roof that could be considered as a strategy for retrofitting roofs in existing buildings, and a solution for improving urban environment quality. Furthermore, Capra et al. (2018) indicated monthly energy saving with the application of cool roof, while Gargari et al. (2016) evaluated the energy savings achieved by a green roof coupled with different configurations of external wall.

Retrofit of roofing systems play a key role in helping to achieve energy efficiency improvements and sustainable development goals. In order to fulfil these objectives, it is necessary to develop sustainable roof retrofitting approaches based on renewable energy sources, appropriate selection of materials, existing climatic conditions, and building characteristics. Proper selection of insulating material is considered to play a crucial role in achieving the desired energy reduction in retrofit roofing systems. A study by Molleti et al. (2018) investigated the use of vacuum insulation panels (VIPs) as a complementary insulation component for integration into existing roofing insulation, namely polyiso systems. The results of the study showed that the VIP composite insulation could reduce the external heat flow during typical winter conditions by $40 \%$.

A number of ongoing roof retrofitting strategies are looking into the implementation of building information modelling (BIM) to optimize the management of refurbishment processes. BIM based tools can provide simulation and visualization options for sustainable development and refurbishment projects, and can also be used to minimize uncertainties in building energy modeling processes and energy-driven retrofits. A BIMbased approach can play a significant role in finding the 
optimal solutions (e.g., cool roof coatings and compound roof systems) for energy efficient roof retrofitting of existing buildings. For example, Saafi and Daouas (2018) studied the thermal performance of residential building roofs regarding impact of thermal insulation and cool coatings by using EnergyPlus software (US Department of Energy, 2018), which showed economic and environmental benefits of cool roofs.

A range of roof waterproofing membranes should also be considered to choose from for design of thermal upgrade and expected moisture management performance. Such an approach offers efficient installation methods for both refurbishment and new build applications in the field of roofing systems. In fact, use of a proper membrane system is important for roof retrofitting system based on heat transfer and thermal performance analysis, as well as waterproofing criteria. This process is determined by calculating some loads based on building location and height.

In this context, BIM can potentially provide fundamental information about heat transfer and thermal performance. BIM models can be used to simulate heat and moisture transfer through a multi-layered roof. A study reported by Chan and Chow (2013) developed methods for evaluation of overall thermal transfer value through building envelope. The objective of this study was for validation of the building energy simulation program EnergyPlus incorporated with the green roof model Ecoroof.

Determination of thermal performance and evaluation of heat transfer through building envelopes is an essential part of energy modeling analysis. Minimization of transfer of heat into building is a key factor to foster energy conservation. Besides envelope systems, roofs can also make a significant contribution to reduce heat conduction as well as energy losses. In terms of environmental benefits, development of appropriate roofing retrofit systems can reduce urban heat island effect and protect buildings from solar radiation directly. Hence, it is important to develop appropriate sociotechnical and sustainability interventions toward sound strategies for roofing retrofit systems.

\section{Energy-Efficient Building Materials for Refurbishments}

Assessment of building materials in terms of energy efficiency has become one of the most important factors in the built environment. In order to conduct energy efficient and sustainable refurbishments, it is necessary to consider the amount of energy consumed by the materials used in construction and maintenance of buildings during their life cycle. Energy-efficient materials can play a key role in promoting energy conservation and carbon reduction in the field of building retrofitting.

The selection of appropriate materials along with providing better thermal properties (thermal resistance/transmittance and conductibility) is an important part of energy efficiency retrofit projects. The most common insulation materials such as Polyisocyanurate (PIR) and polyurethane (PUR) foam, mineral wool, molded expanded polystyrene (EPS), extruded expanded polystyrene (XPS), fibreboard, perlite board, corkboard, and cellular glass are being widely used in roofs.

In recent years, roof slab insulation techniques have been extensively developed due to their architectural flexibility and environmental adaptability. For example, a study by Romeo and Zinzi (2013) achieved a 54\% energy saving by applying a cool paint for roof slab. Halwatura and Jayasinghe (2008) developed a system to reduce heat loss by $75 \%$ using a $25 \mathrm{~mm}$ polystyrene layer. A study reported by Nandapala and Halwatura (2016) designed a durable roof slab insulation system that can reduce the heat gain into a building by more than $75 \%$ for tropical climatic conditions. This study highlighted that roof slab insulation is very important to mitigate and adapt to global warming.

Elastomeric roof coatings including BUR (built-up roofing), bitumen, metal, cement, and EPDM (ethylene propylene diene terpolymer) are considered to be effective solutions for retrofitting of deteriorated roof slab systems. Some of these solutions can significantly reduce energy consumption and provide long-term benefits. Furthermore, most of these solutions are able to adjust to changing climate conditions throughout the year.

As a widely used roofing system, EPDM or rubber roofing system is a single-ply rubber roofing membrane that can accommodate various temperatures because of its flexibility. It is also resistant to damage from environmental effects and is one of the most costeffective roofing options available that can be used for low-sloping roofs. EPDM membranes can be installed fully adhered, mechanically attached or ballasted.

\section{Solar Panels}

Roof top solar photovoltaic (PV) systems are considered as part of a holistic approach to sustainable development. In order to promote the deployment of these systems in buildings, it is necessary to consider available solar radiation and rooftop area. Furthermore, the integration of a significant quantity of rooftop PV needs a flexible grid, supporting infrastructure, and a suite of enabling technologies (Gagnon et al. 2016). In order to estimate the energy production of a PV array, several factors should be taken into account, including classification of buildings by rooftop suitability, proper roof orientation, and determination of optimum tilt angle of solar collectors based on local climate conditions. In order to determine the technical potential of rooftop PV, NREL researchers have used ranging (lidar) data or high-resolution aerial photographs, which can be used to measure the amount of sunlight hitting roofs across, shading and roof tilt. In this respect, the PV potential for small (residential) vs medium/large buildings (commercial) has been determined by combining lidar data, geospatial analyses, and simulations across all areas of the continental U.S. (Figure 1). According to 
research results, rooftop PV can provide 1.1 TW of electrical power and $1432 \mathrm{TWh}$ of annual energy generation.

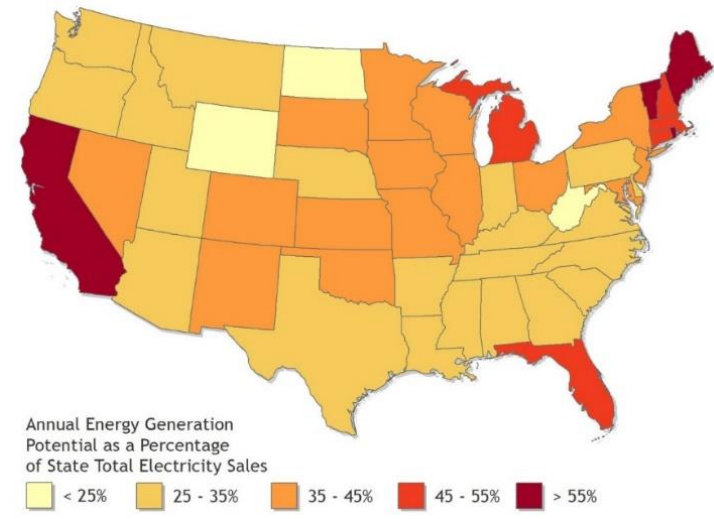

Figure 1: Potential rooftop PV annual generation from all buildings as a percentage of each state's total electricity sales in 2013 (Gagnon et al. 2016).

The study reported by Singh and Banerjee (2013) proposed a methodology to estimate rooftop area from Google Earth images. Another study by Mewes et al. (2017) investigated methods for photovoltaic installations on existing buildings by using simulation software PVsyst. A study by Luqman et al. (2015) highlighted the applicability of ArcGIS to determine building slope and irradiance for additional assessment of residential rooftops.

Needless to say, integration of photovoltaic technologies in the built environment is becoming increasingly recognized as the most convenient and attractive option for renewable energy production. However, its dependence on effective installation techniques has been associated with potential reduction in power output of PV arrays when used as an integral building element. Building-integrated photovoltaic (BIPV) is a smart energy production system and used to promote solar energy strategies by incorporating solar PV panels in parts of the building envelope such as roof, wall, and window. Youssef et al. (2018) developed a novel optimization method for BIPV shape development based on the shape grammar theory. The study highlighted that this method can be used to find the optimal building envelope design for maximizing PV integration. Along with BIPV, building integrated photovoltaic/thermal systems (BIPV/T) are more likely to produce electricity and heat at the same time. They combine the solar thermal and solar photovoltaic components in a single unit (Figure 2). They are considered to have the greatest potential for use in solar energy conversion.

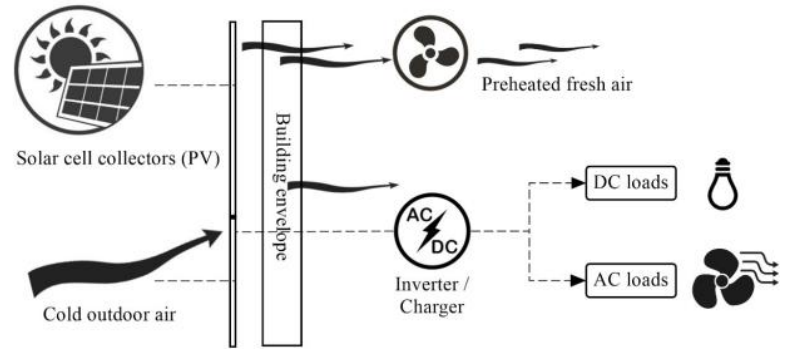

Figure 2: Schematic illustration of BIPV/T systems.

In general, due to large availability of unused roof space, BIPV systems installed on rooftops are being increasingly used. BIPV systems are commonly classified into five main categories: BIPV's foil systems or thin film systems, BIPV's tile systems, BIPV's module systems, BIPV's solar cell glazing systems and building attached photovoltaic (BAPV) systems. Accordingly, due to their superior flexibility and minimal weight properties, BIPV foil systems can be considered for enabling seamless integration of PV onto buildings. They play an important role in maximizing energy harvesting and facilitating possibilities for a variety of applications.

\section{Existing Building Roof System Assessment}

New Kensington is one of the least-populated small towns in the U.S., and besides single-family houses, there are low-rise apartment buildings with multiple functionality. New Kensington was successful in obtaining enterprise zone designation for approximately 1,100 acres in late 2005 .

New Kensington is also the name of a branch campus of The Pennsylvania State University located near the town of New Kensington. The University has been helping in revitalization efforts for the city of New Kensington. Some work is currently underway on design of Smart Homes, which are computer-monitored homes for the elderly. Building refurbishment is another focus area in revitalization programs that will likely become more common in New Kensington's building sector, and therefore, it is important to assess the environmental impacts associated with these processes. The development of low-carbon sustainable refurbishment solutions can be considered for residential buildings in New Kensington. This process can also lead to development of a set of methods for selecting the most suitable renewable energy systems based on specific parameters that have been widely used in practice.

For cities like New Kensington that is defined as a cold region-Zone 5 (Figure 3), sustainable refurbishment approaches should be taken to prepare for mainstream deployment of renewable energy and low-carbon materials. In order to assess the carbon emissions of each sustainable refurbishment approach in a building renovation project, it is necessary to estimate the carbon footprint of each product across the entire supply chain. In this work, assessment of an existing building roof is used in order to develop sustainable refurbishment options. 


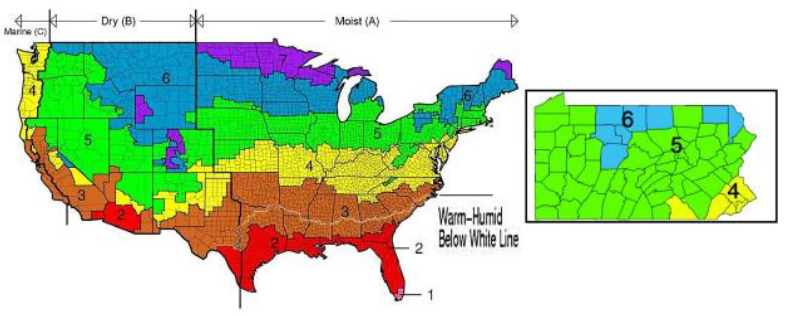

Figure 3: International Energy Conservation Code (IECC) climate zone map.

The building under study is called Dattola Theatre located on 1021 5th Avenue in New Kensington and is currently under consideration to be refurbished and retrofitted (Figure 4).

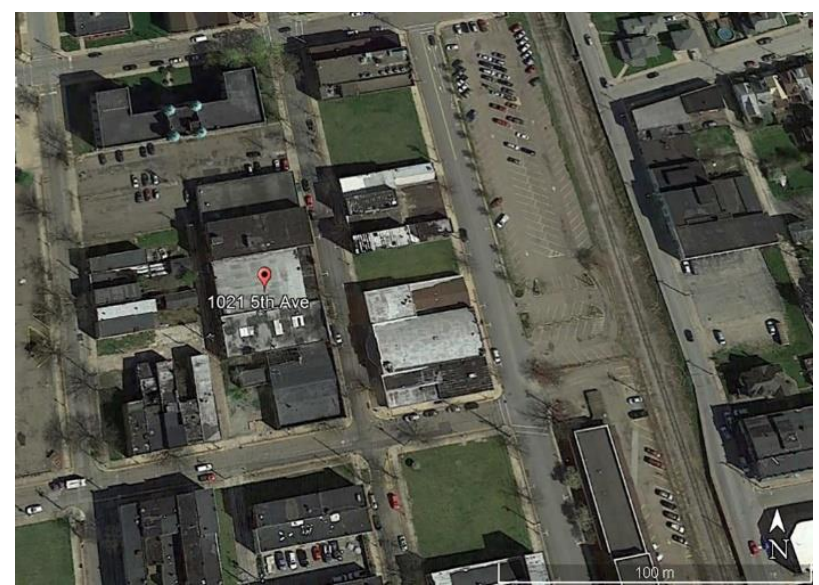

Figure 4: Site plan of existing building in New Kensington.

The building was built in 1942 back when New Kensington was a prosperous town. The building that is on a sloping terrain is comprised of two floors with a structural system composed of solid masonry walls and a concrete shell. It is desirable to carry out a deep refurbishment and to maintain the building in working condition with minimum cost and energy consumption.

The refurbishment of the building is intended to initially address the problems of the existing roof system. The desirable solution is to include a wide range of sustainable materials and economic development features. The existing roof system is deteriorated, and adding a new roof on top of the existing flat roof seems to be the logical choice. The finishing of existing roof is a rubber roof membrane, while the ceiling under the roof is mainly made of aluminum and steel with panels from a wide range of materials that have been deteriorated, leading to leakage of roof rainwater onto the theatre floor below. There is also the chance of the drain pipe from the roof to ground level becoming clogged. According to an on-site survey, the existing roof is a built-up roof and has a low pitch (Figure 5).
It is important to note that the performance of a building's roof can affect the mechanical and physical properties of materials used in the structure, which in turn can determine the degree to which a building is sustainable. Therefore, it is necessary to define a set of factors that have implications on the performance of a building's roof. Although refurbishment of a sloped roof can be accomplished by covering of roofing materials and elements, there is still great potential for an economic and environmental design of renovation concepts.
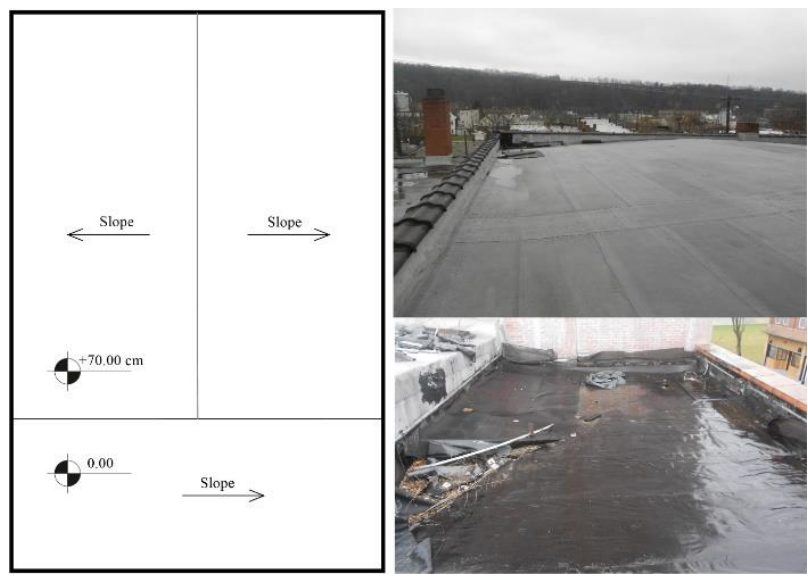

Figure 5: Roof plan of existing building in New Kensington.

A review of existing roof data collection can be used to design a systematic approach for the development of sustainable refurbishment concepts. Although there are several barriers to clearly identify existing roof assemblies and rooftop structures, the unknowns can be determined by a documentation and systematic analysis of the roof's structural components.

\section{Guideline for Existing Roof Assembly Evaluation}

It is expected that sustainable refurbishment will be effective in reducing the amount of GHGs emitted by existing buildings. In order to address sustainable refurbishment with high-energy efficiency, it is imperative to better understand the difficulties in the replacement of existing roofing systems with retrofit materials. For example, the design of re-roofing systems follows the same principles that can be applied to new construction, including the adaptive response and reuse of existing materials. Therefore, consideration should be given to the development of appropriate building materials that are compatible with existing roof system in order to improve thermal performance, efficiency and sustainability.

\section{Thermal insulation}

In order to help choose the most appropriate solution for refurbishment projects, it is important to create multiple viable options and then provide a comparison. Accordingly, one can find considerable number of 
different example details for different existing conditions that can be used for comparison. For example, a built-up roofing system can be used to provide long lasting elastomeric roofing protection and installed directly over existing roofing materials (Figure 6).

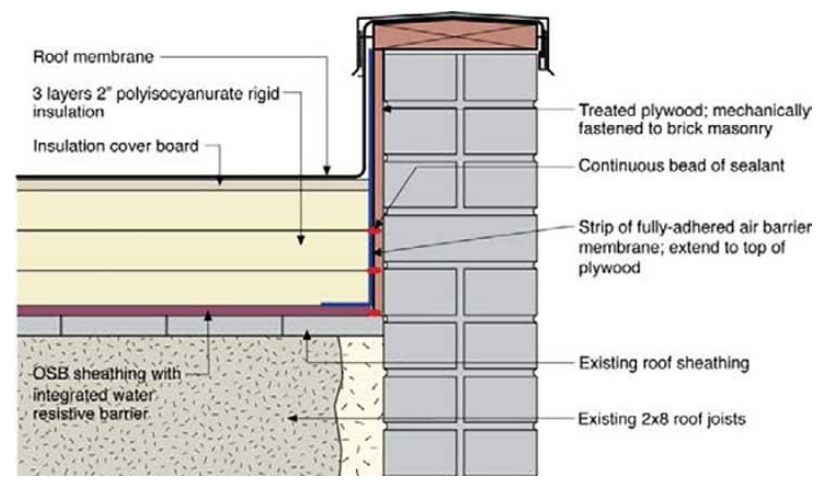

Figure 6: Example of built-up roofing system (US Department of Energy, 2015).

As can be seen from Figure 6, it is important that the retrofit solutions include rigid insulation. Furthermore, although multi-layer membrane roofing is a proven system, there are quite a few benefits for single-ply membrane roofing systems. For example, EPDM singleply membranes can be chemically adhered to insulation or ballasted creating a layer of protection against roofing system failures.

Single-ply roofing membranes do not include any insulation property, so rigid insulation should normally be added to most commonly used deck types before EPDM installation. They can be designed for installation in conjunction with $\mathrm{PV}$ for cost effective construction projects.

Given the importance of considering sustainable refurbishment as a decision factor, an example design of the roofing system is presented for retrofit of the existing system. The proposed new roof conceptually employs appropriate material such as solar coating, ballast paver, EPDM membrane, sheathing, and rigid insulation to promote the integrity and the environmental sustainability of existing roof system (Figures 7 and 8).

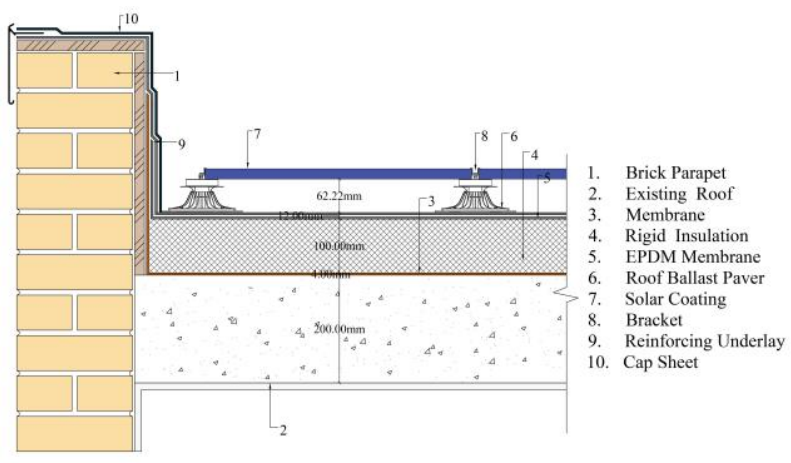

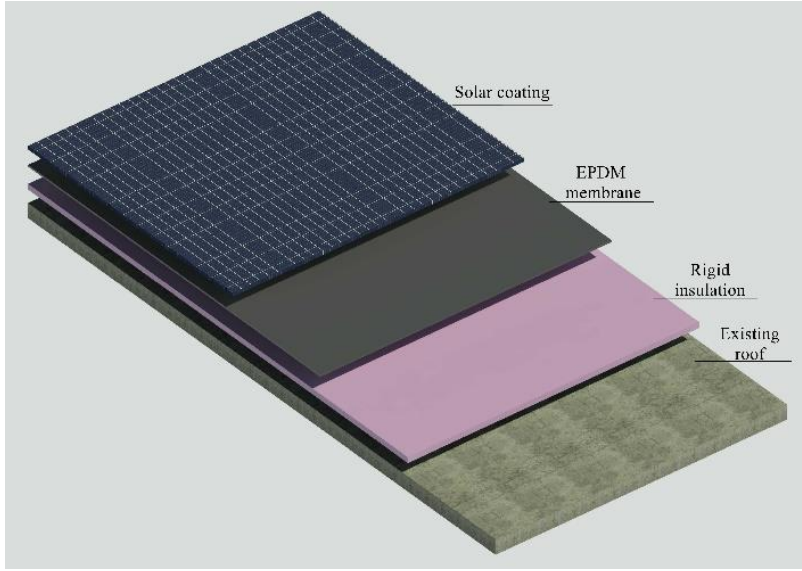

Figure 8: 3D illustration of the proposed detail.

The suggested solution allows the solar coating to absorb most of the solar radiation and capture much more energy. Furthermore, the proposed ballast pavers that are lightweight panels can be used as a platform base structure, where the open joints between panels and their slight elevation above the roofing membrane allow drainage under the panels (Figure 9). The EPDM membrane is one of the most widely used roofing membrane types. It is widely used in low-slope buildings and can play a key role in waterproofing applications subject to roof retrofit /replacement.

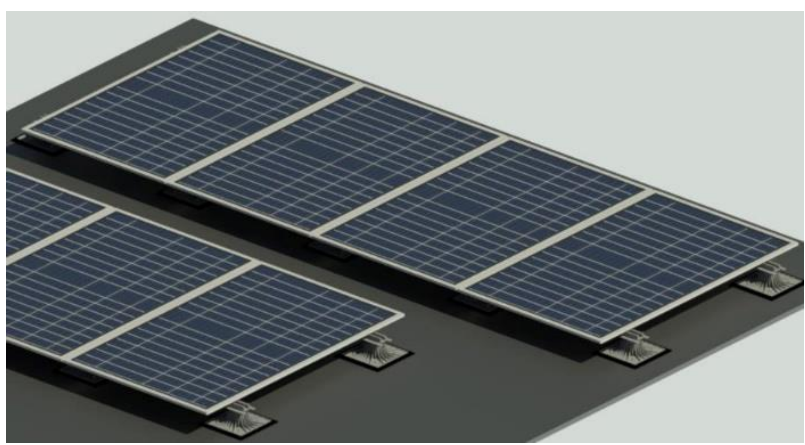

Figure 9: 3D illustration of solar coating systems and the proposed ballast pavers.

\section{Data Analysis}

In order to make a preliminary calculation of the available rooftop area $\left(7,867.8 \mathrm{ft}^{2}\right)$, HelioScope tool (2018) was utilized. HelioScope is an integrated photovoltaic design tool (a web-based tool) and can be used to evaluate location and design a photovoltaic system. A Google Photo was used to illustrate the layout of the proposed photovoltaic system on rooftop of the chosen existing building (The Dattola Theatre). The detail shown in Figure 10 was used in order to assess the location and evaluate the performance of the solar photovoltaic systems.

Figure 7: Proposed detail of new roof. 


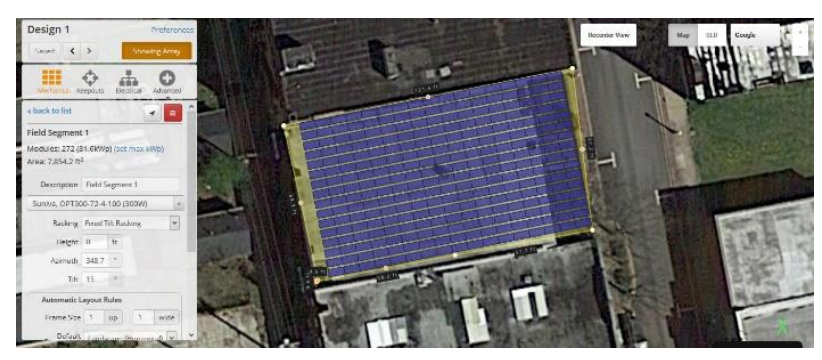

Figure 10: A map detailing photovoltaic system on rooftop of the existing building.

\section{The electricity generation}

In order to investigate the energy generating performance of PV systems, separate specifications such as module, inverter, module orientation, electrical design segments, and weather data were determined. Furthermore, PV modules were sized to fit the available rooftop area and optimized to maximize energy production throughout the year. It is important to note that in design of the module configuration, placement of the panels has been considered to be flat in order to avoid shading losses. Due to weather and climate, shading, wiring, component efficiencies, panel mismatches losses are taken into account when estimating energy production.

The simulation results of the available rooftop area in the form of monthly production is demonstrated in Figure 11. The total system production is calculated as 89.99 MWh/year including all losses assumed by HelioScope (Figure 12). Based on the simulation results, the maximum electric energy production is in July $(12,480.3$ $\mathrm{kWh}$ ) and the minimum is in December 2,035.7 (kWh). Furthermore, total power capacity of all inverters in the system is $68.0 \mathrm{~kW}$.

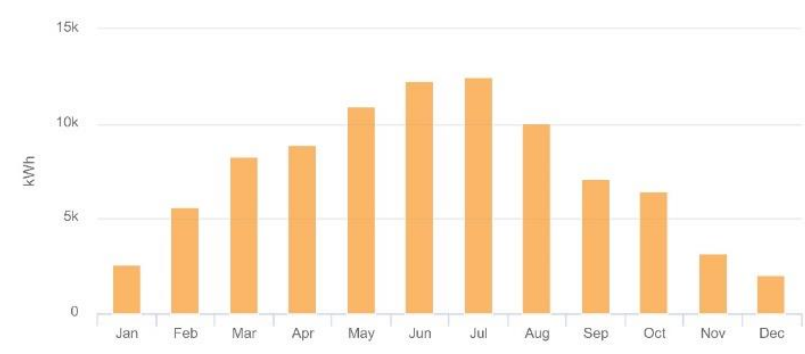

Figure 11: Produced electricity from the installed system on the existing building. The months in $x$-axis are belong to 2018 year.

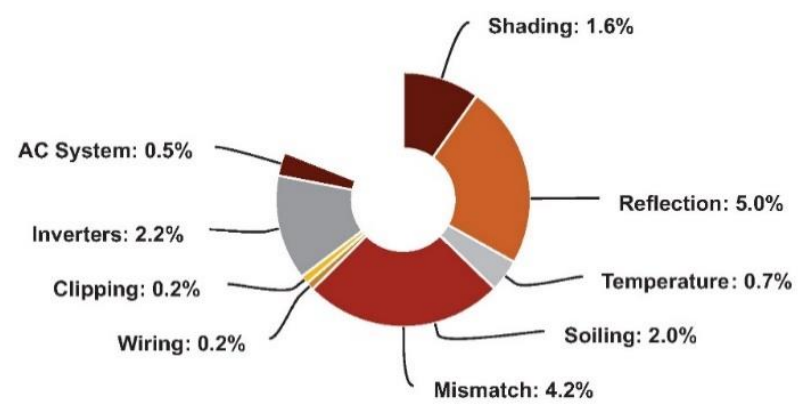

Figure 12: Illustration of sources of system loss.

\section{Results}

It is clear that heat flux through the roof can be reduced by using appropriate insulation. In general, insulation tends to be more effective in heating-dominated buildings in colder climates and is less effective in cooling-dominated buildings with large internal heat loads in warmer climates ( $\mathrm{Li}$ et al., 2013). In order to investigate the efficiency of the proposed roof concept, a simple approach to modeling and simulation of external conduction gain was performed by using Integrated Environmental Solutions Virtual Environment (IES-VE) software (2018). At the first step in the simulation, two zones (zone 1 and zone 2) based on different levels of the roof of the existing building were determined (Figure $13)$.

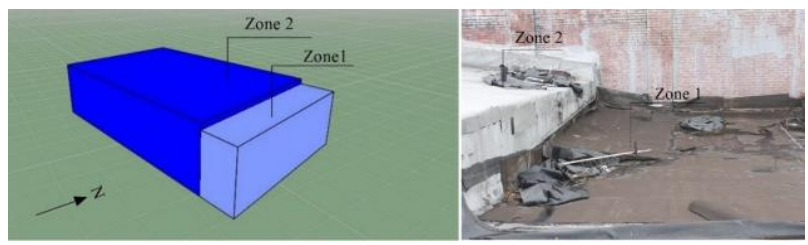

Figure 13. Illustration of zone boundaries the existing building.

In this context, asphalt and reinforced concrete pavement are considered as the materials used in existing roof covering. Thermal properties of walls and floor covering materials are regarded as constant values. An analysis of external conduction heat gain from building envelope was carried out (Figure 14). It is noted that the surrounding neighboring buildings are located in the long side of the building facing North and South. 


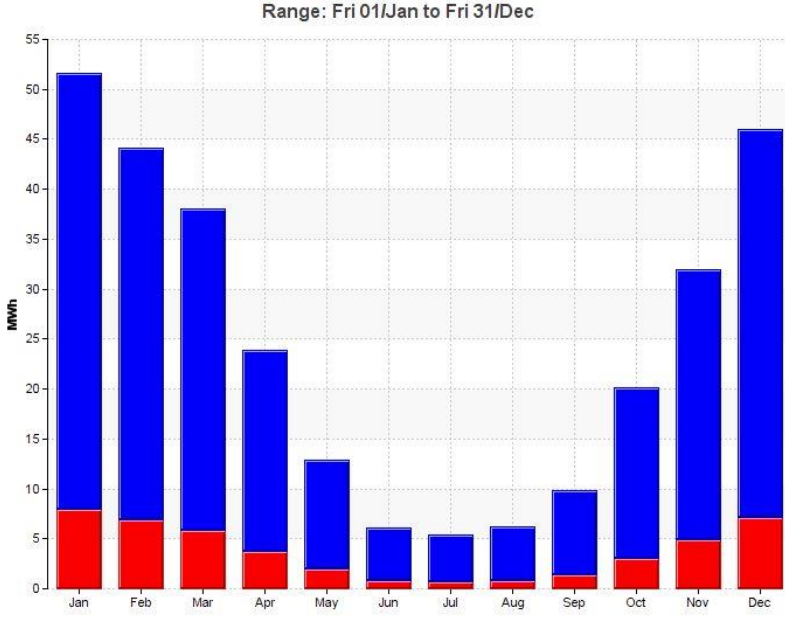

Figure 14. External conduction gain through building envelope in Zone 1 (red column) and Zone 2(blue column).

The summary deducted from the total of the Figure 14 shows that zone 1 and zone 2 covering $15 \%$ and $85 \%$ of the existing roof's surface area and have total 45.33 MWh and 250.77 MWh external conduction gain, respectively.

The roofing system is the most important target for extra insulation, especially in colder climate. In this respect, a simulation study was performed in order to measure insulation added (rigid insulation 100mm and EPDM membrane $12 \mathrm{~mm}$ ) within the existing roof system based on the proposed detail (Figure 15).

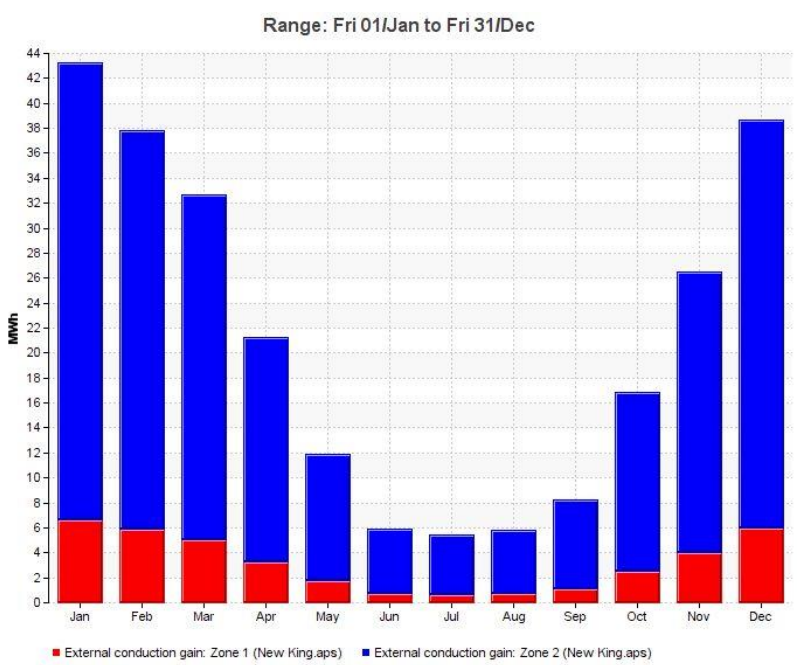

Figure 15. External conduction gain through roof in Zone 1 (red column) and Zone 2(blue column) with insulation added.

According to results from the analysis of external conduction heat gain with insulation added within the existing roof system, total loads of zone 1 and zone 2 have been reduced from 45.33 MWh to $38.43 \mathrm{MWh}$ (15.22\% \% improvement) and from $250.77 \mathrm{MWh}$ to
215.93 MWh (13.89\% improvement), respectively. This is the change from existing condition to the retrofitted condition. It is important to mention that this was only one example showing how the performance can be improved. In fact, the increasing insulation levels have a more significant effect on reducing external conduction heat gain, which is a major mode of heat transfer through building envelope. The only purpose for modeling and simulating was to determine roof insulation requirement for more detail. The energy modelling analysis was compared to original design with no solar panels. The power output of photovoltaic solar panels was calculated separately and is not included in the energy saving mentioned.

\section{Conclusion}

The literature review summarized in this study and the approach presented are expected to provide a general basis for improving flat roof refurbishments in a similar climate. These findings are meant to lead to providing energy savings for existing buildings. There are a large variety of roof refurbishment methods based on architectural design and local climate conditions. The most common and cost-effective approach for roof systems was proposed and commented on during the analysis.

This study also shows the significance of integrating solar panel systems in construction or renovation projects. This study highlights that roof systems should be appropriately detailed and considered when undertaking design and refurbishment projects. The application of an appropriate rooftop system can lead to improved energy savings. Further work is also required to estimate combining material and installation costs as well as investment payback time estimates.

\section{References}

Capra B., Seifhashemi M., Milller W. and Bell J. (2018). The potential for cool roofs to improve the energy efficiency of single storey warehouse-type retail buildings in Australia: A simulation case study. Energy and Buildings, 158, 1393-1403.

Cascone S., Catania F., Gagliano A. and Sciuto G. (2018). A comprehensive study on green roof performance for retrofitting existing buildings. Building and Environment, 136, 227-239.

Chan A. and Chow T. (2013). Evaluation of Overall Thermal Transfer Value (OTTV) for commercial buildings constructed with green roof. Applied Energy, 107, 10-24.

Chen J., Peng Z., and Yang P. P.-J. (2019). The Energy Performance Evaluation of Roof Retrofit Under Uncertainties for the Shanghai's Worker Village. Energy Procedia, 158, 3170-3176.

Fan Y. and Xia X. , "A Multi-objective Optimization Model for Building Envelope Retrofit Planning," Energy Procedia, vol. 75, pp. 1299-1304, 2015. 
Gagnon P., Margolis R., Melius J., Phillips C. and Elmore R. (2016). Rooftop Solar Photovoltaic Technical Potential in the United States. A Detailed Assessment. The National Renewable Energy Laboratory (NREL), Technical Report.

Gargari C., Bibbiani C., Fantozzi F. and Campiotti C. A. (2016). Simulation of the Thermal Behaviour of a Building Retrofitted with a Green Roof: Optimization of Energy Efficiency with Reference to Italian Climatic Zones. Agriculture and Agricultural Science Procedia, 8, 628-636.

Halwatura R. and Jayasinghe M. (2008). Thermal performance of insulated roof slabs in tropical climates," Energy and Buildings, 40, 1153-1160.

HelioScope, Solar PV calculator software. (2018) http://www.folsomlabs.com/about [accessed 10/04/18].

Integrated Environmental Solutions Virtual Environment (IES-VE), (2018). https://www.iesve.com/ [accessed $10 / 04 / 18]$.

Li D. H., Yang L. and Lam J. C. (2013). Zero energy buildings and sustainable development implications A review. Energy, 54, 1-10.

Luqman M., Ahmad S. R., Khan S., Ahmad U., Raza A. and Akmal F. (2015). Estimation of Solar Energy Potential from Rooftop of Punjab Government Servants Cooperative Housing Society Lahore Using GIS. Smart Grid and Renewable Energy, 6, 128-139.

Mewes D., Monsalve P., Gustafsson I., Hasan B., Palén J., Nakakido R., Capobianchi E. and Österlund B. (2017). Evaluation Methods for Photovoltaic Installations on Existing Buildings at the KTH Campus in Stockholm, Sweden. Energy Procedia, $115,409-422$.

Molleti S., Lefebvre D. and Reenen D. V. (2018). Longterm in-situ assessment of vacuum insulation panels for integration into roofing systems: Five years of field-performance. Energy and Buildings, 168, 97105.

Nandapala K. and Halwatura R. (2016). Design of a durable roof slab insulation system for tropical climatic conditions. Cogent Engineering, 3.

Pisello A. L., Piselli C. and Cotana F. (2015). Thermalphysics and energy performance of an innovative green roof system: The Cool-Green Roof. Solar Energy, 116, 337-356.
Roberts B., Webber M. and Ezekoye O. (2015).Development of a multi-objective optimization tool for selecting thermal insulation materials in sustainable designs. Energy and Buildings, 105, 358-367.

Romeo C. and Zinzi M. (2013). Impact of a cool roof application on the energy and comfort performance in an existing non-residential building. A Sicilian case study. Energy and Buildings, 67, 647-657.

Saafi K. and Daouas N. (2018). A life-cycle cost analysis for an optimum combination of cool coating and thermal insulation of residential building roofs in Tunisia. Energy, 152, 925-938.

Singh R. and Banerjee R. (2013). Estimation of roof-top photovoltaic potential using satellite imagery and GIS. Proceedings from 39th IEEE Photovoltaic Specialists Conference (PVSC).

Thomsen A.F. and van der Flier C.L. (2008). Replacement or reuse? The choice between demolition and life cycle extension from a sustainable viewpoint. ENHR International Research Conference Shrinking Cities, Sprawling Suburbs, Changing Country sides.

US Department of Energy, EnergyPlus simulation software (Version 8.2), https://energyplus.net/ (accessed October 2018).

US Department of Energy, (2015). Measure Guideline: Deep Energy Enclosure Retrofit (DEER) for Zero Energy House (ZERH) Flat Roofs. Available at: https://www1.eere.energy.gov/buildings/publications /pdfs/building_america/enclosure-retrofit-zerh-flatroofs.pdf [Accessed 15 Dec. 2018].

Youssef A. M., Zhai Z. J. and Reffat R. M. (2018). Generating proper building envelopes for photovoltaics integration with shape grammar theory. Energy and Buildings, 158, 326-341.

Zhou Z., Zhang S., Wang C., Zuo J., He Q. and Rameezdeen R. (2016). Achieving energy efficient buildings via retrofitting of existing buildings: a case study. Journal of Cleaner Production, 112, 36053615 . 